\title{
Delivered growth factor therapy to improve healing after rotator cuff repair
}

This article was published in the following Dove Press journal:

Stem Cells and Cloning:Advances and Applications

8 October 2010

Number of times this article has been viewed

\section{Emilie V Cheung \\ Luz Silverio \\ Jeffrey Yao}

Department of Orthopedic Surgery, Stanford University, Redwood City, CA, USA
Correspondence: Emilie V Cheung Department of Orthopedic Surgery, Stanford University, 450 Broadway Street, MC 6342, Redwood City, CA 94063, USA Tel + I 6507217627

Fax + I 6507213470

Email evcheung@stanford.edu
Background: Degenerative rotator cuff tears are a significant cause of shoulder pain in the aging population. Rotator cuff repair surgery may be more successful when growth factors are delivered to the repair site. This study was designed to determine the cellular processes involved in normal bone-to-tendon healing and the current approaches used for biologic augmentation of rotator cuff repair.

Methods: This review focuses on animal studies of rotator cuff repair and early human trials. Results: Regular bone-to-tendon healing forms a fibrous junction between tendon and bone that is markedly different from the original bone-to-tendon junction. Tendon augmentation with cellular components serves as scaffolding for endogenous fibroblastic cells and a possible source of growth factors and fibroblastic cells. Extracellular matrices provide a scaffold for incoming fibroblastic cells. However, research in extracellular matrices is not conclusive due to intermanufacturer variation and the lack of human subject research. Growth factors and platelet-rich plasma are established in other fields of research and show promise, but have not yet been rigorously tested in rotator cuff repair augmentation.

Conclusions: Rotator cuff repair can benefit from biologic augmentation. However, research in this field is still young and has not yet demonstrated that the benefits in healing rates are significant enough to merit regular clinical use. Randomized controlled trials will elucidate the use of biologic augmentation in rotator cuff repairs.

Keywords: rotator cuff, shoulder pain, growth factors, repair

\section{Introduction}

Incidence rates of degenerative rotator cuff tears increase with age. ${ }^{1}$ A cadaveric study demonstrated that the incidence of full-thickness rotator cuff tears in subjects older than 60 years was $30 \%$, compared with $6 \%$ in those younger than 60 years. $^{2}$ As the population increases in age, degenerative rotator cuff tears will become an increasingly prevalent clinical problem.

Despite multiple surgical techniques to improve bone-to-tendon healing, recurrent tearing of the rotator cuff is not infrequent. Postoperative rotator cuff retears occur in as little as $11 \%$ to as much as $94 \%$ of rotator cuff repair surgeries, perhaps depending on the size of the tear and the level of tendon degeneration. ${ }^{1,3-38}$ Retear rate correlates with decreased functional outcome after rotator cuff repair. ${ }^{29}$ Considering the relatively high percentage of repair failure occurring with current surgical techniques, it is important to explore techniques of rotator cuff biologic augmentation to reduce the retear rates and improve long-term shoulder function.

When considering an appropriate biologic treatment for rotator cuff tears, it is important to consider their etiology. Although rotator cuff tears can occur via acute injury, most 
rotator cuff tears occur as a result of a gradual degeneration of the tendon and the bone-to-tendon interface. ${ }^{31}$

The normal bone-to-tendon interface involves the interdigitation of layers of intact, oriented Type I collagenous fibers to a continuous insertion on the humerus. ${ }^{39}$ The vasculature is organized and dispersed throughout the tendon. Vessels decrease in size and number as distance to the bone decreases. ${ }^{39}$ Longitudinally, there are four distinct zones of tissue, ie, tendon, nonmineralized fibrocartilage, mineralized fibrocartilage, and bone. ${ }^{40}$

When the tendons within the rotator cuff begin to degenerate, the collagenous fibers undergo hyaline and myxoid degeneration, and the bone undergoes chondroid metaplasia. Inflammation, calcification, vascular proliferation, and fatty infiltration are also present. ${ }^{41}$ Importantly, these tendinous changes are visible throughout the damaged tendon, not just at the site of rupture. ${ }^{42}$ These degenerative changes are often macroscopically visible during surgical repair. ${ }^{15}$

A full understanding of normal healing processes and the scientific approaches toward augmenting these healing processes during rotator cuff repair is necessary to improve the healing of degenerative and traumatic rotator cuff tears after repair. We investigated the current research to determine the cellular processes involved in normal bone-to-tendon healing, as well as the approaches being developed in tendinous augmentation with cellular components and acellular extracellular matrix (ECM) augmentation, and the addition of growth factors.

\section{Biology of bone-to-tendon healing}

In normal bone-to-tendon healing, the final bone-to-tendon insertions ultimately have little resemblance to the native insertion site. Instead of four distinct zones, the bone and tendon are joined by a layer of fibrovascular scar tissue predominated by Type III collagen. ${ }^{22,42}$ This tissue is weaker than the original insertion site and may contribute to the substantial number of repair failures. Bone-to-tendon healing can be divided into three stages, ie, the inflammatory stage, the repair stage, and the remodeling stage. ${ }^{43}$

The inflammation cascade is a complex tissue response and involves a number of different cytokines and recruited cells that fluctuate in number as the rotator cuff repair continues. ${ }^{43}$ The inflammatory stage begins within the first week of rotator cuff repair and is characterized by the infiltration of neutrophils and recruited macrophages. These recruited macrophages secrete transforming growth factor $\beta 1$ (TGF- $\beta 1$ ), which increases proteinase activity and collagen formation. ${ }^{44}$ These early-recruited macrophages contribute to the formation of fibrovascular scar tissue. It is likely TGF- $\beta 1$ secretion is the mechanism of scar tissue formation in the presence of recruited macrophages. Local macrophages are also present in smaller numbers in the repairing bone-totendon insertion point. Local macrophages are thought to have a positive anabolic function opposed to the catabolic function observed in the recruited macrophages. ${ }^{44}$

Inflammation may also perform important functions in increasing the strength of bone-to-tendon interfaces. In a mouse knockout study, Lin et $\mathrm{al}^{10}$ demonstrated that complete removal of a proinflammatory cytokine, interleukin 6 , resulted in decreased mechanical function and collagen fiber continuity. Additionally, inflammation often presents after tendon overuse and may serve as a protective mechanism in usual tissue injury. ${ }^{19}$

Several growth factors have been implicated in the repair stage of natural bone-to-tendon healing. Bone morphogenic protein (BMP) 12 to 14, expressed in active fibroblasts and heavily involved in de novo joint formation, were present throughout the healing process of the bone-to-tendon insertion. ${ }^{35}$ Basic fibroblast growth factor (bFGF), which increases fibroblastic proliferation while suppressing collagen formation, is also present. ${ }^{45}$ Insulin-like growth factor 1 (IGF-1), which stimulates protein synthesis and cell proliferation while decreasing swelling, has been observed in the healing bone-to-tendon junction. ${ }^{45}$ Platelet-derived growth factor $\beta$ (PDGF- $\beta$ ), correlated with increased levels of Type I collagen, is also present in low levels throughout the repair. ${ }^{8,46}$ Although the repair stage of healing classically begins at the end of the first week, Randelli et $\mathrm{al}^{20}$ report that some of these cytokines appear immediately after surgical repair procedures. Fifteen minutes after performing arthroscopic acromioplasty and other shoulder procedures on patients, $3 \mathrm{~mL}$ of liquid was removed from the subacromial space and from the venous blood supply. Levels of TGF- $\beta$, PDGF- $\beta$, and bFGF were measured in each liquid. For each growth factor, levels in the subacromial space were markedly higher than levels in the serum. These observations indicate growth factors may be equally important during the beginning of the healing process as toward the end. ${ }^{20}$

Vascularity of the tendinous region also contributes to rotator cuff tears and therefore may also contribute to the repair of those tears. Within a tendon, vascularity decreases at the point of the tear as compared with its interface on bone. ${ }^{47}$ Although no studies have directly proven a causal relationship between increased vascularity and improved rotator cuff healing, a recent randomized, prospective clinical trial has demonstrated that a topically applied angiogenic 
factor, glyceryl trinitrate, reduced shoulder pain and stiffness in patients with chronic supraspinatus tendinopathy. ${ }^{18}$

\section{Repair strategies \\ Tendon augmentation with cellular components}

Transplanted tendon can be used to decrease the repair tension between tendon and bone. In addition, using tendons may help with the biologic process of recovery, either by providing a growth scaffold for cells or by populating the bone-to-tendon junction with donor cells and growth factors. This does not require tissue matching in any way. In a rat model of acute rotator cuff tears treated with cellular grafts, Iwata et $\mathrm{al}^{48}$ found the host cell commenced proliferation in the interposed graft tendon. However, it is unknown if the host cells retain their active role in rotator cuff healing in the setting of a degenerative or avascular tear.

Tendon transplants can come from either allogenic or autogenic sources. Moore et $\mathrm{al}^{17}$ repaired massive rotator cuff tears in 28 patients with allografts of cadaveric Achilles, patellar, or quadriceps tendon. Although the patients demonstrated improved function, the improvements were not superior to those of similar patients who were treated with acromioplasty and debridement alone. Additionally, within the allograft group, there was one case of infection and one case of presumed acute rejection in which intraoperative cultures were negative and no preoperative antibiotics had been taken.

Autograft augmentation, because of the decreased likelihood of rejection, ${ }^{49}$ is generally preferred as a cellular graft material. Several studies have been performed investigating the efficacy of cellular autograft treatments for rotator cuff tears using the tenotomized biceps tendon. ${ }^{21,50}$ In addition to reducing repair tension and providing cellular material, an autograft biceps tendon has two further benefits. First, because it is in the same site of repair, it does not necessitate a primary harvest surgery. Second, because many patients present with a rotator cuff tear and a complicating lesion in the long head of the biceps, they are likely to need tenotomy anyway. Cho et al ${ }^{50}$ retrospectively reviewed massive rotator cuff tears with and without augmented tenotomized biceps. Both procedures were performed arthroscopically and involved standard technique with the exception of the biceps interposition. During the biceps augmentation procedure, the biceps tendon was tenotomized at its origin and passed into the subacromial space. Suture anchors were placed at the greater tuberosity, and limbs of the suture penetrated both the biceps graft and the rotator cuff. The biceps was interposed between the lateral edge of the cuff and the tuberosity. There was no difference in pain, range of movement, or clinical outcome 12 months postoperatively. However, patients who underwent biceps augmentation demonstrated greater strength and lower structural failure rate (41\% failure with augmentation and $73.7 \%$ without augmentation).

\section{ECM augmentation}

Other augmentations to rotator cuff tears minimize the potential problem of graft rejection by using acellular material. In the repair site, an ECM with no cellular components acts as a tissue bridge between shortened tendon and bone, and its matrix can act as an effective scaffold for aligned cellular growth and collagen assembly. ${ }^{51}$ These augmentations are currently available in three forms, ie, xenograft, allograft, and synthetic extracellular matrices.

ECMs formed from xenogenic or allogenic material must first be rigorously processed in order to remove any cellular material. Although this process varies among manufacturers and is often proprietary, general decellularization techniques can be organized into three approaches, ie, physical, chemical, and enzymatic. ${ }^{32,35}$ The physical decellularization approach uses snap freezing or mechanical agitation to lyse the native cells in the harvested tissue. ${ }^{9,52}$ The chemical decellularization approach lyses native tissue cells with hypotonic solutions or detergents. The cellular remnants are then solubilized and removed from the ECM in sequential washing steps. ${ }^{34}$ Enzymatic decellularization uses trypsin to degrade cellular material and can be used in conjunction with a solubilizing detergent. ${ }^{16}$ Complete decellularization of a xenograft or an allograft will include one or more of the above approaches.

The use of xenograft ECM in rotator cuff repairs has yielded mixed results. One xenograft ECM, Restore ${ }^{\circledR}$ (DePuy Orthopaedics, Richmond, VA) is a collagen-based material made from porcine small intestine mucosa. In a randomized control trial of the Restore patch, Iannotti et a ${ }^{53}$ demonstrated no improvement in patients with Restore augmentation when compared with patients who underwent the same procedure without xenograft addition. More recently, Restore was found to contain a relatively high level of DNA within its matrix $(1.13 \pm 0.01 \mathrm{ng} \mathrm{DNA} / \mathrm{mg}$ dry weight $)$ and has also resulted in an inflammatory result in $20 \%$ of patients whose rotator cuff tears were repaired with Restore augmentation. ${ }^{14,54}$ Therefore, the authors recommended that this product not be used.

The Zimmer ${ }^{\circledR}$ Collagen Repair Patch, marketed as Permacol $^{\circledR}$ (Tissue Science Laboratories PLC, Aldershot, Hampshire), is a porcine dermal graft with no measurable DNA in its matrix and no reported inflammatory responses 
in patients. ${ }^{54}$ One retrospective analysis of rotator cuff repair using Permacol showed improved functional scores by $50 \%$ at 4.5 years post-repair. ${ }^{55} \mathrm{It}$ is unclear whether the improvements compared favorably with individuals with similar rotator cuff tears repaired without xenograft augmentation because no control group was used in this study. ${ }^{55}$ Another study investigated the use of Permacol in bridging gaps in massive rotator cuff tears. ${ }^{27}$ Retear rates were not lower than massive rotator cuff repairs performed without augmentation.

TissueMend ${ }^{\circledR}$ (TEI Biosciences, Boston, MA) and CuffPatch $^{\circledR}$ (Arthrotek, Warsaw, IN) are two other commercially available xenografts. A study comparing rotator cuff repairs augmented with Restore, Cuffpatch, TissueMend, Permacol, and GraftJacket ${ }^{\circledR}$ (Wright Medical Technology, Arlington, TN) demonstrated that rotator cuff repairs augmented with CuffPatch experienced substantial inflammation when compared with the other grafts. ${ }^{32}$ Another similar study demonstrated that TissueMend had higher levels of DNA embedded in the ECM when compared with other xenograft materials. ${ }^{56}$ No additional studies have been performed using these xenografts in rotator cuff repair.

Allogenic extracellular matrices have been developed via decellularization of cadaveric material. Despite differences between allogenic ECM and autogenic cellular tendon, equivalence has been demonstrated between autografts and allogenic ECM. Adams et $\mathrm{al}^{51}$ compared cellular autografts with an allogenic ECM (GraftJacket) in a canine rotator cuff repair model. During the first six weeks, rotator cuffs repaired with cellular autograft augmentation showed better recovery and repair than those repaired with allogenic ECM. After 12 weeks, however, the rotator cuffs repaired with allogenic ECM and the rotator cuffs repaired with autogenic tendon were equivalent in strength and histologic measurement. ${ }^{51}$

There are two commercially available allogenic ECMs that have been studied to date, ie, the Allopatch ${ }^{\circledR}$ (Musculoskeletal Tissue Foundation, Edison, NJ), an allogenic ECM made from harvested human fascia lata, and GraftJacket, made from human dermal tissue. The two graft materials are comparable in terms of stiffness, strength, and tissue retention. ${ }^{57}$ However, only GraftJacket has been studied extensively in terms of rotator cuff repair augmentation. When compared with other graft materials, GraftJacket demonstrates a higher load-to-failure than Permacol, TissueMend, Restore, and CuffPatch, but is still notably weaker than the native uninjured autologous tendon. ${ }^{56,58}$

Ide et a ${ }^{59}$ found rotator cuff tears repaired with allogenic ECM (GraftJacket) augmentation had higher tendon maturing scores than an untreated control defect group, demonstrated greater mean ultimate force to failure than the defect group, and performed better histologically and mechanically at every point in the study. Cadaveric studies comparing allogenicaugmented rotator cuff repairs (GraftJacket) to rotator cuff repairs without augmentation demonstrated that the use of human dermal allograft increased the strength of the repaired tendon; the mean failure strengths were $325 \pm 74$ $\mathrm{N}$ with allogenic ECM and $273 \pm 116 \mathrm{~N}$ without allogenic ECM. ${ }^{55}$ There are, however, limited human subject data comparing repair using allogenic augmentation with repair of comparable tears without allogenic augmentation. Bond et $a^{60}{ }^{60}$ showed that repairing massive rotator cuff tears with allogenic augmentation (GraftJacket) yielded a failure rate of $19 \%$. This result is lower than the $38 \%-95 \%$ failure rate demonstrated in several studies evaluating nonaugmented massive rotator cuff repairs. ${ }^{3,5,6,38} \mathrm{~A}$ histologic assessment of one patient's allogenically augmented rotator cuff repair (GraftJacket) demonstrated no calcification, infection, or inflammatory response at three months. Collagen was well aligned and little blood vessel ingrowth was observed, demonstrating improved bone-to-tendon healing with allograft ECM augmentation. ${ }^{26}$

However, there are potential problems with allogenic ECMs. Allogenic ECMs can still contain some DNA from their allogenic source and may induce inflammatory responses in the host..$^{54}$ These inflammatory responses can cause pain and edema at the site of repair and may increase the degeneration of the rotator cuff repair that has been documented in the initial degenerative process of the rotator cuff. ${ }^{37}$ They are also less elastic than autogenic tendon, which may result in comparably increased retear rates due to decreased load-carrying abilities. ${ }^{56}$

Because concern remains that allograft materials may create an inflammatory response, there is considerable interest in developing synthetic ECM grafts for surgical use. Synthetic ECMs may still serve as an adequate scaffold for cellular and fibrotic growth, while running a smaller risk of provoking an inflammatory response than allograft ECMs. Several animal studies have investigated the benefit of augmenting rotator cuff repair with synthetic ECMs.

One study used a polyglycolic acid (PGA) sheet to augment rotator cuff repairs of infraspinatus tendons in Japanese white rabbits ${ }^{36}$ and showed histologic improvement in fibrocartilage layering, but only a slight improvement in tensile strength when compared with control tendons augmented with another slowly absorbing synthetic material. ${ }^{36} \mathrm{~A}$ similar experiment performed by Funakoshi et al ${ }^{61}$ demonstrated increased fibroblast presence and collagen formation when 
synthetic ECM was surgically applied to rotator cuff tears. In this experiment, a $10 \mathrm{~mm}$ surgical defect was created at the humeral insertion of the infraspinatus tendon in 21 Japanese white rabbits. In one shoulder, the $10 \mathrm{~mm}$ defect was covered with chitin, a biodegradable polymer, sutured into the bone trough and attached to the free end of the infraspinatus tendon. The contralateral shoulder was left untreated as a control. Throughout the experiment, tendon-to-bone junctions covered with chitin fabric demonstrated greater cell number, better collagen fiber alignment, and greater mechanical strength than the tendon-to-bone junctions left free as a control. ${ }^{61} \mathrm{~A}$ third study using polylactic acid patches in goats showed no observable difference between the treated and control groups. ${ }^{13}$ Derwin et a ${ }^{62}$ performed a similar experiment using a woven poly-L-lactide device. The superior two-thirds of each infraspinatus tendon was removed from the rotator cuff and then repaired in both shoulders of mongrel dogs. In one shoulder, a woven polyL-lactide device was placed over the repair. In the other shoulder, the repair was left nonaugmented. The augmented rotator cuff repair resulted in fewer tendon retractions, greater strength, and increased stiffness when compared with the contralateral untreated rotator cuff repairs.

Several studies recently reported using ECMs as a scaffold for autogenic cells in vitro, as well as in rotator cuff repair. First, autologous cells are harvested from undamaged sites on the host, such as patellar ligaments, fascia lata, or other tendinous structures, by a small biopsy punch. They are then washed in an antibiotic medium, digested with collagenase, and filtered to remove any matrix debris. After the cells have been appropriately purified, they are cultured in incubation flasks alone for several days and then cultured with the ECM for up to five days to seed the matrix appropriately in vitro. This construct of allogenic, xenogenic, or synthetic ECM and autogenic cells has several potential applications.

ECM autogenic cell constructs can be incubated in appropriate media and result in engineered autogenic tendons. These tendons have been investigated as augmentation materials in the repair of rotator cuff tears. Chen et $\mathrm{al}^{63}$ modeled the effect of using such engineered tendons to augment rotator cuff tears in Japanese white rabbits. Tenocytes were harvested from patellar ligaments, purified using markers for Types I and III collagen expression, and then implanted onto xenogenic and synthetic ECMs. Fibers were cultured for five days to allow for appropriate tenocyte matrix formation. Rotator cuff tears were created in the infraspinatus tendon and then repaired with genetically engineered tendon, ECM, or autologous tendon. When compared with ECM augmentation alone, augmentation with engineered autologous tendon resulted in increased Types I and III collagen deposition, decreased immunologic response, and improved absorption into the host tendon. Augmentation with engineered autologous tendon was comparable with the autogenic cellular augmentation performed as a control.

Harvesting autologous tenocytes from undamaged tendon to engineer new tendon can result in a secondary injury, prohibiting their clinical use. To circumvent this problem, Liu et $\mathrm{al}^{11}$ demonstrated in a porcine extensor tendon model that ECMs seeded with dermal fibroblasts are equivalent to ECMs seeded with tenocytes in the formation of in vitro tendons. This suggests that tenocytes are acting through the secretion of growth factors.

ECM autogenic cell constructs can also be manipulated via gene therapy. Dines et al ${ }^{64}$ investigated repair of rotator cuff tears using interposed genetically engineered autologous tendon in Sprague Dawley rats. Tenocytes were isolated from the rotator cuff and then transduced with the genes for PDGF- $\beta$ or IGF-1, two factors known to promote fibroblast proliferation and minimize inflammation. The transduction was performed using a retroviral vector. Successfully transduced cells were again isolated, seeded onto PGA, and used to augment rotator cuff repair. When incorporated into rotator cuff repair, the tendons transduced with PDGF- $\beta$ showed no improvement over controls augmented with PGA matrix alone or simple repair. However, the tenocytes transduced to express IGF-1 exhibited an improvement in both toughness and maximum load. The growth factors Dines et al ${ }^{64}$ chose to transpose represent only two of a handful of known growth factors involved in de novo tendon formation and wound healing. Gene therapy in genetically engineered autogenous tendons is a promising delivery system for growth factors required for appropriate tendon healing, and further investigation here is warranted.

\section{Growth factor addition}

The studies previously discussed have focused on adding structural support to the rotator cuff repair, with possibly a beneficial cellular contribution in some cases. However, if the cellular benefits offered by grafts can be attributed to the factors secreted by the graft's cells, the direct application of those growth factors may be a more direct therapy. The following approaches consider the addition of growth factors to healing rotator cuff repairs to provide increased biologic support.

Several individual growth factors have been tested independently for their contribution to rotator cuff healing. Osteoinductive proteins have been examined for their role 
in rotator cuff healing. In a sheep infraspinatus tear model, growth factors from bovine cortical bone extract (BMP-2 to BMP-7, TGF- $\beta 1$ to TGF- $\beta 3$, and FGF) were implanted into a healing rotator cuff with a Type I collagen sponge. ${ }^{23}$ The investigators found increased bone volume, soft tissue volume, and failure loads in the augmented group when compared with nonaugmented control. However, when the loads were normalized for tissue volume, they observed no differences between treated and untreated shoulders. The data suggest that while the bovine cortical bone extract may have accelerated the healing process, it did not change the quality of the repair. ${ }^{23}$

The addition of recombinant human BMP-12 to acute full-thickness tears in sheep demonstrated a similar result. ${ }^{25}$ Repairs with recombinant human BMP augmentation showed increased strength and rigidity compared with untreated repairs by $300 \%$. However, tissues in both augmented and control arms of the study exhibited similar mechanical properties when normalized to the size of the tendon. ${ }^{25}$

TGF- $\beta$ has also been identified as an important growth factor in bone-to-tendon healing, although one report suggests the application of TGF- $\beta$ to injured tendons yielded increased proliferation without necessarily increasing tendon strength. ${ }^{42}$ In vivo, these growth factors work in concert to create appropriate bone-to-tendon healing but it is unlikely a great change will be observable through the application of individual growth factors. Because of this, there is a great amount of interest in the creation of "platelet-rich plasma" (PRP) by centrifuging autologous blood to purify a dense, suturable plasma matrix. ${ }^{20} \mathrm{PRP}$ includes many of the growth factors identified previously as crucial in normal bone-totendon healing, ie, TGF- $\beta$, bFGF, PDGF, vascular endothelial growth factor, connective tissue growth factor, and epidermal growth factor. ${ }^{65}$

PRP has been explored in other fields as a promising biologic augmentation for healing. A prospective, randomized trial investigated the addition of PRP grafts to surgical sites of hysterectomies and other major gynecologic surgeries involving uterine tissue. The results demonstrated that patients who received a PRP graft experienced decreased postoperative pain when compared with a control group. ${ }^{57,63}$ In another prospective, randomized trial, Cieslik-Bielecka et $\mathrm{al}^{66}$ demonstrated that the application of platelet-rich gel to mandibular odontogenic cysts increased oral mucosal healing. Although other surgical procedures have been investigated using PRP as an augmentation, there are not much data yet concerning the use of PRP in human rotator cuff repair.
Animal studies investigating the role PRP might play in bone-to-tendon healing yield promising results. An in vitro study investigating PRP in gene expression patterns, DNA, and collagen content of equine tendon showed that injured tendons treated with PRP expressed increased levels of Type I collagen, Type III collagen, and cartilage oligomeric matrix protein when compared with untreated control tendons. ${ }^{24}$

Although PRP has yet to prove itself as a biologic augmentation to rotator cuff tears, one human subject study has investigated the safety of PRP augmentation to rotator cuff repair. A total of 14 patients undergoing arthroscopic repair of a rotator cuff tear received an intraoperative application of autologous PRP in combination with an autologous thrombin component after tear repair. The authors concluded application of PRP during arthroscopic rotator cuff repair is safe and effective, without any adverse events. ${ }^{20}$ Further prospective studies are needed to investigate the effect of PRP on rotator cuff healing and ultimate shoulder function.

\section{Stem cells}

Biologic augmentation of rotator cuff healing by the implementation of mesenchymal stem cells is being studied. Gulotta et $\mathrm{al}^{21}$ studied the effect of membrane Type 1 matrix metalloproteinase (MT1-MMP), which is normally upregulated during embryogenesis in areas that develop into tendon-bone insertion sites. In a rat supraspinatus tendon tear model, bone marrow-derived stem cells were transduced with adenoviral MT1-MMP, and the presence of fibrocartilage and collagen fiber orientation at the insertion site was compared with that of mesenchymal stem cells in a fibrin glue carrier (MSP group). The hypothesis was that stem cells transduced with MT1-MMP will drive the healing process toward regeneration of tendon tissue rather than the formation of scar tissue. At four weeks, the MT1-MMP group had more fibrocartilage ( $P=0.05)$, higher ultimate load to failure $(P=0.01)$, higher ultimate stress to failure $(P=0.005)$, and higher stiffness values $(P=0.02)$ compared with the MSC group. The authors concluded that mesenchymal stem cells genetically modified to overexpress the developmental gene MT1-MMP can augment rotator cuff healing at four weeks in this rat model by the presence of more fibrocartilage at the insertion and improved biomechanical strength. Biologic augmentation of repaired rotator cuffs with MT1-MMPtransduced MSCs may improve healing. However, further studies are needed to determine if this remains safe and effective in larger models.

Mazzocca et $\mathrm{al}^{22}$ reported on their process of obtaining and purifying connective tissue progenitor cells during 
arthroscopic rotator cuff repair. Bone marrow aspirates were harvested through the anchor tunnel of the humeral head during arthroscopic rotator cuff repair in 23 patients. Reverse transcription polymerase chain reaction analysis and cellular staining confirmed the osteogenic potential of these connective tissue progenitor cells. There was no statistical significant difference in the single assessment numeric evaluation score (aspirate, $86.3 \pm 10.5$; control, $83.6 \pm 15.1 ; P=0.54$ ), range of motion measures (postoperative external rotation: aspirate, $65.0^{\circ} \pm 20.4^{\circ}$; control, $62.5^{\circ} \pm 17.1^{\circ} ; P=0.67$ postoperative forward elevation: aspirate, $163.0^{\circ} \pm 30.6^{\circ}$; control, $145.7^{\circ} \pm 41.4^{\circ} ; P=0.12$ ), or postoperative strength measures between groups (median, 5; range, $4-5$ in the aspirate group compared with median, 5; range, 4-5 in the control group; $P>0.05$ ). The authors concluded that connective tissue progenitor cells can be safely and efficiently aspirated from the proximal humerus with their technique during arthroscopic rotator cuff surgery. These cells may play an important role in cell-based therapies involving rotator cuff repair and enhance the healing process

\section{Discussion}

Rotator cuff tears are becoming increasingly frequent as the population ages. Decreasing postoperative tear rates of rotator cuff repairs will serve to diminish joint morbidity greatly and improve the general efficacy of surgery. Biologic augmentation strategies should be considered when attempting to improve repair rates. In this paper, we investigated the biologic approaches currently under study in the field of rotator cuff repair.

There are several limitations to consider. Although many growth factors and cellular processes have been identified in the normal bone-to-tendon healing process, each growth factor has a multitude of functions and it is difficult to elucidate each of these functions in a complex healing process. Our knowledge regarding exact mechanisms for rotator cuff healing is therefore limited by the inability to identify the functions of individual growth factors definitively in the healing process. When considering biologic augmentation, it is difficult to ascertain the true benefit of using any biologic augmentation without a solid comparative trial available. For cellular tendon augmentation, only autologous tendon grafts with a tenotomized biceps tendon have been definitively proven to improve surgical outcome..$^{50}$ ECMs are difficult to endorse without well-designed intermanufacturer comparison. Additionally, animal studies showing host cell repopulation of the bone-to-tendon junction used ECMs to repair simulated traumatic rotator cuff repairs. ${ }^{48}$ It is unclear whether host cells of degenerative rotator cuff tears will behave similarly to those of traumatic rotator cuff tears. The addition of PRP and other growth factors has been shown to decrease pain and improve healing in several studies without causing recovery problems, ${ }^{20,49,66}$ but its addition to rotator cuffs has not yet been studied in a randomized control trial.

Normal bone-to-tendon healing is characterized by a three-stage process. ${ }^{63}$ The first stage is an inflammatory stage with increased levels of neutrophils, macrophages, and TGF$\beta 1$, which play dominant roles in the formation of typical scar tissue seen in repaired rotator cuffs. ${ }^{44}$ Other inflammatory cytokines, including interleukin 6 , may be responsible for increasing the strength of the new scar tissue. ${ }^{10} \mathrm{BMP}, \mathrm{bFGF}$, IGF-1, PDGF- $\beta$ are all involved in the repair and remodeling stage of normal bone-to-tendon healing. These growth factors have been identified as positive factors in the normal healing of rotator cuffs and are responsible for de novo joint formation, fibroblastic proliferation, edema prevention, and increased levels of Type I collagen, respectively. ${ }^{28,35,45,46}$

The knowledge of bone-to-tendon healing is being leveraged in several ways. One approach focuses on augmenting rotator cuff repairs with tendinous materials containing cellular components. Allogenic cellular tendon grafts have been associated with no marked improvement in functional outcome and have been associated with infection and graft rejection. ${ }^{17}$ Autogenic cellular tendon grafts are currently being and improve healing, strength, and overall function. ${ }^{50}$

The use of ECMs as a scaffolding system for fibroblasts and collagen matrices has yielded mixed results, depending on the patch manufacturer. One of the most researched xenogenic ECMs, Restore, was used by many surgeons based on preliminary research results until a randomized control trial performed by Iannotti et $\mathrm{al}^{53}$ demonstrated that the use of the ECM did not markedly improve functional scores or retear rates, and in some patients even provoked increased inflammation. Other ECMs (GraftJacket, Permacol, Tissuemend, CuffPatch) have limited research demonstrating favorable recoveries in rotator cuff repairs but have not been analyzed in any randomized control trial or indeed in any comparative trial in human patients to establish improved repair strength.

When considering allogenic ECMs, all major studies have been performed using GraftJacket as a graft material. Because the Allopatch ${ }^{\circledR}$ has been developed only recently, it has not been as thoroughly investigated. It would be worthwhile to investigate whether the qualities we attribute to GraftJacket can be applied to other allogenic graft matrices or if the qualities are 
manufacturer-specific, in which case similar studies performed on Allopatch would be extremely informative.

An important role that ECMs may begin to play in the future is as scaffolding for implanted autologous tenocytes or fibroblasts genetically engineered to produce growth factors conducive to tendinous growth. ${ }^{11,30,63,64}$ Although the current biology involved in these processes is complicated, time-intensive, and expensive, it is true that many fields are focusing on using genetic engineering to solve medical problems. A byproduct of their investigations may result in a model of genetic engineering and cell purification that is both quick and cheap. It would be highly beneficial for researchers involved in biologic augmentation to be prepared with applications for this technology when it has become readily accepted in medical treatment.

Addition of separate growth factors (BMP-2 to BMP-7, BMP-12, TGF- $\beta 1$ to TGF- $\beta 3$, and FGF) increases bone volume, soft tissue, volume, and failure loads when compared with normal tendon. ${ }^{23,25,42}$ PRP, a milieu of growth factors in addition to platelets, decreased pain, and improved healing in several studies not related to rotator cuff repair. ${ }^{49,66}$ A case study using PRP in rotator cuff repairs demonstrated that the plasma was safe for use but did not compare the augmented rotator cuff repairs with any control. ${ }^{20}$ The next step in this field of research is to perform a randomized, controlled study using PRP as an augmentation to rotator cuff repairs to appropriately assess whether PRP truly makes an improvement in rotator cuff repair.

Many of the new and promising applications of biologic augmentation have not yet been rigorously tested in humans. Further human subject research will both illuminate the use of biologic augmentation for rotator cuff repairs and develop future protocols for appropriate augmentation techniques and materials.

\section{Disclosure}

Each author certifies that he or she has no commercial associations (eg, consultancies, stock ownership, equity interest, and/or patent/licensing arrangements) that might pose a conflict of interest in connection with this work.

\section{References}

1. Takahashi S, Nakajima M, Kobayashi M, et al. Effect of recombinant basic fibroblast growth factor (bFGF) on fibroblast-like cells from human rotator cuff tendon. Tohoku J Exp Med. 2002;198:207-214.

2. Kinsella K, Velkoff VA. An Aging World: 2001. Washington, DC: US Government Printing Office; 2001.

3. Bishop J, Klepps S, Lo IK, Bird J, Gladstone JN, Flatow EL. Cuff integrity after arthroscopic versus open rotator cuff repair: A prospective study. J Shoulder Elbow Surg. 2006;15:290-299.
4. Boileau P, Brassart N, Watkinson DJ, Carles M, Hatzidakis AM, Krishnan SG. Arthroscopic repair of full-thickness tears of the supraspinatus: Does the tendon really heal? J Bone Joint Surg Am. 2005;87:1229-1240.

5. Galatz LM, Ball CM, Teefey SA, Middleton WD, Yamaguchi K. The outcome and repair integrity of completely arthroscopically repaired large and massive rotator cuff tears. J Bone Joint Surg Am. 2004;86: 219-224.

6. Gerber C, Fuchs B, Hodler J. The results of repair of massive tears of the rotator cuff. J Bone Joint Surg Am. 2000;82:505-515.

7. Lafosse L, Brzoska R, Toussaint B, Gobezie R. The outcome and structural integrity of arthroscopic rotator cuff repair with use of the double-row suture anchor technique. J Bone Joint Surg Am. 2008;90: 275-286.

8. Levy O, Venkateswaran B, Even T, Ravenscroft M, Copeland S. Midterm clinical and sonographic outcome of arthroscopic repair of the rotator cuff. J Bone Joint Surg Br. 2008;90:1341-1347.

9. Lin P, Chan WC, Badylak SF, Bhatia SN. Assessing porcine liverderived biomatrix for hepatic tissue engineering. Tissue Eng. 2004; 10:1046-1053.

10. Lin TW, Cardenas L, Glaser DL, Soslowsky LJ. Tendon healing in interleukin-4 and interleukin-6 knockout mice. J Biomech. 2006;39: 61-69.

11. Liu W, Chen B, Deng D, Xu F, Cui L, Cao YL. Repair of tendon defect with dermal fibroblast engineered tendon in a porcine model. Tissue Eng. 2006; 12:775-788.

12. Longo UG, Franceschi F, Ruzzini L, et al. Histopathology of the supraspinatus tendon in rotator cuff tears. Am J Sports Med. 2008;36: 533-538.

13. MacGillivray JD, Fealy S, Terry MA, Koh JL, Nixon AJ, Warren RF. Biomechanical evaluation of a rotator cuff defect model augmented with a bioresorbable scaffold in goats. J Shoulder Elbow Surg. 2006;15: 639-644.

14. Malcarney HL, Bonar F, Murrell GA. Early inflammatory reaction after rotator cuff repair with a porcine small intestine submucosal implant: A report of 4 cases. Am J Sports Med. 2005;33:907-911.

15. Matthews TJ, Hand GC, Rees JL, Athanasou NA, Carr AJ. Pathology of the torn rotator cuff tendon - reduction in potential for repair as tear size increases. J Bone Joint Surg Br. 2006;88:489-495.

16. McFetridge PS, Daniel JW, Bodamyali T, Horrocks M, Chaudhuri JB. Preparation of porcine carotid arteries for vascular tissue engineering applications. J Biomed Mater Res A. 2004;70:224-234.

17. Moore DR, Cain EL, Schwartz ML, Clancy WG Jr. Allograft reconstruction for massive, irreparable rotator cuff tears. Am J Sports Med. 2006;34:392-396

18. Paoloni JA, Appleyard RC, Nelson J, Murrell GA. Topical glyceryl trinitrate application in the treatment of chronic supraspinatus tendinopathy: A randomized, double-blinded, placebo-controlled clinical trial. Am J Sports Med. 2005;33:806-813.

19. Perry SM, McIlhenny SE, Hoffman MC, Soslowsky LJ. Inflammatory and angiogenic mRNA levels are altered in a supraspinatus tendon overuse animal model. J Shoulder Elbow Surg. 2005; 14 Suppl 1:79S-83S.

20. Randelli PS, Arrigoni P, Cabitza P, Volpi P, Maffulli N. Autologous platelet rich plasma for arthroscopic rotator cuff repair: A pilot study. Disabil Rehabil. 2008;30:1584-1589.

21. Gulotta LV, Kovacevic D, Montgomery S, Ehteshami JR, Packer JD, Rodeo SA. Stem cells genetically modified with the developmental gene MT1-MMP improve regeneration of the supraspinatus tendonto-bone insertion site. Am J Sports Med. 2010 Apr 16 [Epub ahead of print].

22. Mazzocca AD, McCarthy MB, Chowaniec DM, Cote MP, Arciero RA, Drissi H. Rapid isolation of human stem cells (connective tissue progenitor cells) from the proximal humerus during arthroscopic rotator cuff surgery. Am J Sports Med. 2010 Apr 7 [Epub ahead of print].

23. Rhee YG, Cho NS, Lim CT, Yi JW, Vishvanathan T. Bridging the gap in immobile massive rotator cuff tears: Augmentation using the tenotomized biceps. Am J Sports Med. 2008;36:1511-1518. 
24. Rodeo SA, Arnoczky SP, Torzilli PA, Hidaka C, Warren RF. Tendon-healing in a bone tunnel: A biomechanical and histological study in the dog. J Bone Joint Surg Am. 1993;75:1795-1803.

25. Rodeo SA, Potter HG, Kawamura S, Turner AS, Kim HJ, Atkinson BL. Biologic augmentation of rotator cuff tendon-healing with use of a mixture of osteoinductive growth factors. J Shoulder Elbow Surg. 2007;89:2485-2497.

26. Schnabel LV, Mohammed HO, Miller BJ, et al. Platelet rich plasma (PRP) enhances anabolic gene expression patterns in flexor digitorum superficialis tendons. J Orthop Res. 2007;25:230-240.

27. Seeherman HJ, Archambault JM, Rodeo SA, et al. rhBMP-12 accelerates healing of rotator cuff repairs in a sheep model. J Bone Joint Surg Am. 2008;90:2206-2219.

28. Snyder SJ, Arnoczky SP, Bond JL, Dopirak R. Histologic evaluation of a biopsy specimen obtained 3 months after rotator cuff augmentation with GraftJacket matrix. Arthroscopy. 2009;25:329-333.

29. Soler JA, Gidwani S, Curtis MJ. Early complications from the use of porcine dermal collagen implants (Permacol) as bridging constructs in the repair of massive rotator cuff tears: A report of 4 cases. Acta Orthop Belg. 2007;73:432-436.

30. Spindler KP, Murray MM, Detwiler KB, et al. The biomechanical response to doses of TGF-beta 2 in the healing rabbit medial collateral ligament. J Orthop Res. 2003;21:245-249.

31. Sugaya H, Maeda K, Matsuki K, Moriishi J. Repair integrity and functional outcome after arthroscopic double-row rotator cuff repair: A prospective outcome study. J Bone Joint Surg Am. 2007;89: 953-960.

32. Uhtoff HK, Trudel G, Himori K. Relevance of pathology and basic research to the surgeon treating rotator cuff disease. J Orthop Sci. 2003;8:449-456.

33. US Census Bureau. 2007 American Community Survey 1-year estimates. United States - Age and Sex. 2007. Available at: http:// factfinder.census.gov. Accessed Jan 13, 2009.

34. Valentin JE, Badylak JS, McCabe GP, Badylak SF. Extracellular matrix bioscaffolds for orthopaedic applications: A comparative histologic study. J Bone Joint Surg Am. 2006;88:2673-2686.

35. Walton JR, Bowman NK, Khatib Y, Linklater J, Murrell GA. Restore orthobiologic implant: Not recommended for augmentation of rotator cuff repairs. J Bone Joint Surg Am. 2007;89:786-791.

36. Woods T, Gratzer PF. Effectiveness of three extraction techniques in the development of a decellularized bone-anterior cruciate ligament-bone graft. Biomaterials. 2005;26:7339-7349.

37. Wurgler-Hauri CC, Dourte LM, Baradet TC, Williams GR, Soslowsky LJ. Temporal expression of 8 growth factors in tendon-to-bone healing in a rat supraspinatus model. J Shoulder Elbow Surg. 2007; 16 Suppl 5:S198-203.

38. Yokoya S, Mochizuki Y, Nagata Y, Deie M, Ochi M. Tendon-bone insertion repair and regeneration using polyglycolic acid sheet in the rabbit rotator cuff injury model. Am J Sports Med. 2008;36:1298-1309.

39. Clark JM, Harryman DT. Tendons, ligaments, and capsule of the rotator cuff - gross and microscopic anatomy. J Bone Joint Surg Am. 1992;74:713-725.

40. Gulotta LV, Rodeo SA. Growth factors for rotator cuff repair. Clin Sports Med. 2009;28:13-23.

41. Hashimoto T, Nobuhara K, Hamada T. Pathologic evidence of degeneration as a primary cause of rotator cuff tear. Clin Orthop Relat Res. 2003;415:111-120.

42. Galatz LM, Sandell LJ, Rothermich SY, et al. Characteristics of the rat supraspinatus tendon during tendon-to-bone healing after acute injury. J Orthop Res. 2006;24:541-550.

43. Carpenter JE, Thomopoulos S, Flanagan CL, DeBano CM, Soslowsky LJ. Rotator cuff defect healing: A biomechanical and histologic analysis in an animal model. J Shoulder Elbow Surg. 1998;7: 599-605.

44. Hays PL, Kawamura S, Deng XH, et al. The role of macrophages in early healing of a tendon graft in a bone tunnel. J Bone Joint Surg Am. 2008;90:565-579.
45. Dahlgren LA, Mohammed HO, Nixon AJ. Temporal expression of growth factors and matrix molecules in healing tendon lesions. J Orthop Res. 2005;23:84-92.

46. Kobayashi M, Itoi E, Minagawa $\mathrm{H}$, et al. Expression of growth factors in the early phase of supraspinatus tendon healing in rabbits. $J$ Shoulder Elbow Surg. 2006;15:371-377.

47. Biberthaler P, Wiedemann E, Nerlich AK, et al. Microcirculation associated with degenerative rotator cuff lesions: In vivo assessment with orthogonal polarization spectral imaging during arthroscopy of the shoulder. J Bone Joint Surg Am. 2003;85: 475-480.

48. Iwata Y, Morihara T, Tachiiri H, et al. Behavior of host and graft cells in the early remodeling process of rotator cuff defects in a transgenic animal model. J Shoulder Elbow Surg. 2008;17 Suppl 1: 101S-107S.

49. Fanning J, Murrain L, Flora R, Hutchings T, Johnson JM, Fenton BW. Phase I/II prospective trial of autologous platelet tissue graft in gynecologic surgery. J Minim Invasive Gynecol. 2007;14: 633-637.

50. Cho NS, Yi JW, Rhee YG. Arthroscopic biceps augmentation for avoiding undue tension in repair of massive rotator cuff tears. Arthroscopy. 2009;25:183-191.

51. Adams JE, Zobitz ME, Reach JS, An KN, Steinmann SP. Rotator cuff repair using an acellular dermal matrix graft: An in vivo study in a canine model. Arthroscopy. 2006;22:700-709.

52. Jackson DW, Grood ES, Wilcox P, Butler DL, Simon TM, Holden JP. The effects of processing techniques on the mechanical properties of bone-anterior cruciate ligament-bone allografts. An experimental study in goats. Am J Sports Med. 1988;16:101-105.

53. Iannotti JP, Codsi MJ, Kwon YW, Derwin K, Ciccone J, Brems JJ. Porcine small intestine submucosa augmentation of surgical repair of chronic two-tendon rotator cuff tears: A randomized, controlled trial. J Bone Joint Surg Am. 2006;88:1238-1244.

54. Gilbert TW, Freund JM, Badylak SF. Quantification of DNA in biologic scaffold materials. J Surg Res. 2009;152:135-139.

55. Barber FA, Herbert MA, Boothby MH. Ultimate tensile failure loads of a human dermal allograft rotator cuff augmentation. Arthroscopy. 2008;24:20-24.

56. Derwin KA, Baker AR, Spragg RK, Leigh DR, Iannotti JP. Commercial extracellular matrix scaffolds for rotator cuff tendon repair biomechanical, biochemical, and cellular properties. J Bone Joint Surg Am. 2006;88:2665-2672.

57. Barber FA, Aziz-Jacobo J. Biomechanical testing of commercially available soft-tissue augmentation materials. Arthroscopy. 2009; 25:1233-1239.

58. Barber FA, Herbert MA, Coons DA. Tendon augmentation grafts: Biomechanical failure loads and failure patterns. Arthroscopy. 2006; 22:534-538

59. Ide J, Kikukawa K, Hirose J, Iyama K, Sakamoto H, Mizuta H. Reconstruction of large rotator-cuff tears with acellular dermal matrix grafts in rats. J Shoulder Elbow Surg. 2009;18: 288-295.

60. Bond JL, Dopirak RM, Higgins J, Burns J, Snyder SJ. Arthroscopic replacement of massive, irreparable rotator cuff tears using a GraftJacket allograft: Technique and preliminary results. Arthroscopy. 2008;24:403-409.

61. Funakoshi T, Majima T, Suenaga N, Iwasaki N, Yamane S, Minami A. Rotator cuff regeneration using chitin fabric as an acellular matrix J Shoulder Elbow Surg. 2006;15:112-118.

62. Derwin KA, Codsi MJ, Milks RA, Baker AR, McCarron JA, Iannotti JP. Rotator cuff repair augmentation in a canine model with use of a woven poly-L-lactide device. J Bone Joint Surg Am. 2009;91: $1159-1171$

63. Chen JM, Willers C, Xu JK, Wang A, Zheng MH. Autologous tenocyte therapy using porcine-derived bioscaffolds for massive rotator cuff defect in rabbits. Tissue Eng. 2007;13: 1479-1491. 
64. Dines JS, Grande DA, Dines DM. Tissue engineering and rotator cuff tendon healing. J Shoulder Elbow Surg. 2007;16 Suppl 5: S204-S207.

65. Everts PA, Knape JT, Weibrich G, et al. Platelet-rich plasma and platelet gel: A review. J Extra Corpor Technol. 2006;38:174-187.
66. Cieslik-Bielecka A, Bielecki T, Gazdzik TS, Cieslik T, Szczepanski T. Improved treatment of mandibular odontogenic cysts with plateletrich gel. Oral Surg Oral Med Oral Pathol Oral Radiol Endod. 2008; 105:423-429.

\section{Publish your work in this journal}

Stem Cells and Cloning: Advances and Applications is an international, peer-reviewed, open access journal. Areas of interest in stem cell research include: Embryonic cell stems; Adult stem cells; Blastocysts; Cordblood stem cells; Stem cell transformation and culture; Therapeutic cloning; Umbilical cord blood and bone marrow cells; Laboratory, animal and human therapeutic studies; Philosophical and ethical issues related to stem cell research. This journal is indexed on CAS. The manuscript management system is completely online and includes a quick and fair peer-review system. Visit http://www.dovepress.com/ testimonials.php to read real quotes from published authors.

\footnotetext{
Submit your manuscript here: http://www.dovepress.com/stem-cells-and-cloning-advances-and-applications-journal
} 